\title{
Perceived Social Support, Psychological Capital, and Subjective Well-Being among College Students in the Context of Online Learning during the COVID-19 Pandemic
}

\author{
Liang Huang $^{1}$ (D) Ting Zhang $^{2}$
}

Accepted: 29 July 2021 / Published online: 6 August 2021

(C) De La Salle University 2021

\begin{abstract}
This study examined the relationship between perceived social support and subjective well-being among college students in the context of online learning during the COVID-19 pandemic. 515 college students in China that participated in an online questionnaire investigation were selected as the research sample. The results showed that perceived social support was significantly and positively associated with life satisfaction and positive affect and was significantly and negatively related to negative affect among college students learning online during the COVID19 pandemic. Psychological capital (PsyCap) significantly mediated the relationships between perceived social support and three subjective well-being variables. The present study provides some implications to protect college students' subjective well-being in the context of online learning during the COVID-19 pandemic.
\end{abstract}

Keywords Perceived social support .

Psychological capital · Subjective well-being ·

Online learning · COVID-19

Liang Huang

eliot_huang@163.com

Ting Zhang

christine692@163.com

1 Department of Public Administration, Southeast University, Room 115 Wen Ke Building A Southeast University (Jiu Long Hu Campus), Nanjing, Jiangsu, China

2 Changzhou Senior High School of Jiangsu Province, Changzhou, Jiangsu, China

\section{Introduction}

At the beginning of the year 2020, the outbreak of 2019 novel coronavirus disease (COVID-19) spread quickly across China (The Novel Coronavirus Pneumonia Emergency Response Epidemiology Team 2020). To curb the spread of coronavirus disease and reduce cross-infection, the central government in China decided to postpone the opening of universities, colleges, and schools (The State Council Information Office of the P. R. China, 2020). The Ministry of Education then launched the "School's Out, But Class' On" campaign requiring administrators and teachers from primary to tertiary education to shift to online teaching plan (Zhou et al. 2020). As a result, universities and colleges across China in a short period of time embarked on online education with faculty members delivering lessons in front of computer screens and students taking online courses via the internet (Bao 2020). Although the online learning modality holds promise for maintaining the course delivery and minimizing the disruption of learning routines, it poses additional challenges to college students struggling to survive pandemic-induced uncertainties and fears and adapt to the new way of learning (Dhawan 2020; Hung et al., 2020). For instance, Grubic et al. (2020) pointed out that the unexpected exposure to unfamiliar online instruction would cause more stress for college students who have already suffered heightened levels of mental health problems and undermined subjective well-being during the COVID-19 pandemic.

In the existing literature, research has revealed increased mental disorders (e.g., anxiety, depression, and loneliness) among college students learning online during the pandemic (Besser et al. 2020; Cao et al. 2020). Beyond mental health difficulties, research also found that the sudden implementation of online learning had serious 
consequences on the subjective well-being of college students (Hung et al. 2020; Lyons et al. 2020). In the wake of growing concerns regarding college students' mental wellbeing during the "fully online learning" period, it has become imperative for researchers and practitioners to take actions in ways of helping college students survive the unconventional learning experiences and maintain subjective well-being (American Campus Communities 2020; Chen et al. 2020; Hasan \& Bao 2020). Although emerging research into the subjective well-being of people living through the COVID-19 pandemic has suggested that social support and psychological capital (PsyCap) can be potentially useful resources for humans to cope with stress and maintain mental well-being (Aluh \& Onu 2020; Saltzman et al. 2020), little research has been done to examine the role of such social and personal resources in supporting college students' subjective well-being. To address this noticeable research gap, we in this study examined the relationship between perceived social support and subjective well-being among college students learning online during the COVID-19 pandemic, with a particular interest in the mediating role of PsyCap regarding this relationship.

\section{Literature Review}

\section{Subjective Well-Being among College Students Learning Online during the COVID-19 Pandemic}

Subjective well-being, defined as "a person's cognitive and affective evaluations of his or her life" (Diener et al. 2002, p. 63), is an indispensable contributing component to mental health beyond the absence of mental illness and disorders (de Cates et al. 2015). It is generally accepted that subjective well-being comprises two conceptually distinct but related types of components, namely, the cognitive component denoting evaluations of one's overall life satisfaction and the affective type of components indicating positive and negative emotional responses to life (Busseri \& Sadava 2011; Diener 1994; Kieny et al. 2020). Based on this conceptualization, subjective well-being is measured and assessed as a tripartite construct indexed by (high levels of) life satisfaction and positive affect as well as (low levels of) negative affect (Busseri \& Sadava 2011; Diener 1984). The outbreak of the COVID-19 pandemic and subsequent social distancing have caused disruption to daily routines and chipped away at subjective well-being (Ettman et al. 2020), highlighting an urgent need for researchers and professionals to develop individualized interventions and protect the mental well-being of target populations (Grubic et al. 2020). College students are such a specific group of population whose mental well-being deserves sophisticated attention (Cao et al. 2020; Lyons et al. 2020), especially when the sudden transition to online learning has caused more stress undermining life satisfaction and positive emotions and intensifying negative mood states (American Campus Communities 2020; Hung et al. 2020).

Although online teaching can be regarded as a promising alternative to in-person classes during the period of campus closure (Zhang 2020), it has brought about numerous challenges for colleges students striving to adapt to it (Dhawan 2020). That is, due to tertiary institutions' quick shifting to the online learning modality, college students are left to overcome great online learning shock (American Campus Communities 2020), so as to reduce learning loss and maintain subjective well-being during the period of an unprecedented crisis (Hasan \& Bao 2020). It has been widely reported that, in the context of online learning during the COVID-19 pandemic, college students usually find themselves affected by disrupted learning routines, exposed to unfamiliar and disorientating online instructional methods, confronted with technological obstacles to online learning, and frustrated by deprived inperson interactions (Chen 2020; Cowley 2020; Gasevic 2020; Wong 2020). The pandemic-induced uncertainties and fears together with the stressful online learning experiences have exacerbated college students' psychosocial maladjustment, which may further undermine their subjective well-being (Griffiths et al., 2005; Grubic et al. 2020; Zhang \& Zheng, 2017). To combat the adverse effects of online learning implementation during the COVID-19 pandemic, more research is needed to explore how college students can be supported to maintain subjective wellbeing.

\section{Perceived Social Support and College Students' Subjective Well-Being}

Defined as instrumental, informational, or emotional assistance leading to one's perceptions of being supported and engaged within a supportive social network (Cobb 1976; House et al. 1988), social support has been identified as one of the most significant psychosocial coping resources for people to combat severe mental problems and maintain subjective well-being (Qi et al. 2020). This is especially true for college students who are at a critical stage of exploring and adjusting to the emerging adulthood life and developing personal identity (Arnett 2000). This line of social support research is predicated on the premise that an understanding of available social support from family, friends, and significant others and its psychosocial benefits could inform effective approaches to mental wellbeing among college students (Hefner \& Eisenberg 2009). Social support can be measured as perceived available assistance or actual received ones, and the former can have 
greater influence on mental well-being than the later (Fan \& Lu 2019). Evidence has shown that perceived social support is strongly associated with high college life satisfaction, decreased academic stress and emotional exhaustion, and increased positive feelings (Wang et al. 2018). In contrast, college students lacking social assistance are found incapable of coping with life challenges and academic stress and demonstrating low levels of subjective well-being (Wang, et al. 2014).

In the context of online learning during the COVID-19 pandemic, college students with severe pre-existing mental health problems are exposed to two more layers of stress: the uncertainties and fears of the pandemic and the experiences of online learning shock (American Campus Communities 2020; Grubic et al. 2020). Under such stressful situations, college students may highly rely on the supportive resources and information embedded within their social connections with significant others to relieve stress and anxiety, overcome online learning obstacles, and maintain psychosocial functioning (Saltzman et al. 2020). Although scant research, to our best knowledge, has explored the relationship between perceived social support and subjective well-being among college students learning online during the COVID-19 pandemic, emerging research on the overall population has revealed the particularly important role of supportive social connections with significant others in keeping mental well-being during the period of great threat (Aluh \& Onu 2020). It has been reported that, under the circumstances of school closure and physical distancing, college students have adapted themselves by turning to technology, so as to stay connected with family, friends, and teachers as sources of social support when in need (American Campus Communities 2020). In this study, social support conceptualized as a second-order construct representing college students' perceptions of overall sources of social assistance is hypothesized to be positively related to subjective wellbeing in the context of online learning.

\section{Mediating Role of Psychological Capital (PsyCap)}

According to Luthans et al. (2015), PsyCap refers to an individual's positive psychological development state characterized by four positive psychological resources: efficacy, hope, resilience, and optimism. Efficacy refers to the confidence or beliefs in one's capability to organize or execute certain courses of actions required to produce desired outcomes (Luthans \& Youssef-Morgan 2017). Hope refers to the agentic determination and contingency planning to generate solutions to problems. Resilience refers to the capacity to sustain or bounce back in face of adversity to retain progress. Optimism refers to the positive outlook or expectancy toward events. The positive nature of the constituent resources renders PsyCap as a high-order core construct directly related to positive affective states. As indicated by Youssef-Morgan and Luthans (2015), PsyCap can trigger positive mental well-being through such mechanisms as generating positive cognitive and affective appraisals, facilitating retentions of positive memories, exerting broadening effect when faced with setbacks, and reducing negativity bias. Of note is that PsyCap can be nurtured and enhanced through social mechanisms including social support, constructive relationships, and close contact (Youssef-Morgan \& Luthans 2015).

The existing literature has supported a positive relationship between social support and PsyCap, a synergistic set of positive personal resources that people can rely on to buffer against negative effects of stress and promote subjective well-being (Avey et al. 2009; Pinkerton \& Dolan 2007). Especially in times of adversity, people who have access to social support would be able to take advantage of their high PsyCap to cope with stress and adjust into the turbulent environment (Rabenu et al. 2016). For college students learning online during the COVID-19 pandemic, those who were socially supported may be equipped with high PsyCap, thus enabling their coping with stress and anxiety regarding the uncertainties and fears of the pandemic as well as demanding online learning requirements and tasks (Hefner \& Eisenberg 2009; Luthans et al. 2007). Although no study to date has explored the ways in which social support and PsyCap as a composite coping resource or asset coalesce to support the subjective well-being of college students learning online during the COVID-19 pandemic, it can be hypothesized that college students with more access to social support would have enhanced PsyCap for them to overcome the online learning shock and maintain subjective well-being.

\section{The Present Study}

The sudden outbreak of the COVID-19 pandemic pushed higher education institutions worldwide to shift to online teaching modality in a short period, so as to minimize the impact of the pandemic. China, the first country that implemented social distancing and massive school closure to contain the virus, has seen a large-scale adoption of the online teaching initiative called "School's Out, But Class' On" in nearly all of the universities and colleges (Zhou et al. 2020). While online teaching can be a promising alternative to classroom instruction in times of crisis, it also poses numerous challenges and adds more layers of stress to the life of college students in China (Wong 2020; Ye et al. 2020). In fact, several studies (e.g., Ao et al. 2020, Chang et al. 2020) on college students in China mentioned that the pandemic-induced uncertainties and fears together 
with the online learning shock exacerbated psychosocial maladjustment and undermined subjective well-being. Emerging research also found that supportive relationships with significant others (i.e., family, friends, and teachers) could be tapped for college students to enhance internalized psychosocial capabilities to combat problematic functioning and stay mental well-being and focused on learning (Wu et al. 2020).

Despite emerging research evidence on the importance of social support and PsyCap for subjective well-being during the COVID-19 pandemic (Saltzman et al. 2020; Wu et al. 2020), little research has been conducted to explore how these social and personal mechanisms coalesce to support the subjective well-being of college students. To address the noticeable research gap and to respond to the calls of researchers in China as well as in other countries worldwide for urgent research and immediate solutions to enhance college students' coping resources to address the heightened mental health issue (Chen et al. 2020; Grubic et al. 2020), we examined social support and PsyCap as important coping mechanisms in relation to college students' subjective well-being, as indexed by three discrete components (i.e., life satisfaction, positive affect, and negative affect), in the context of online learning during the COVID-19 pandemic. We further examined the potentially mediating role of PsyCap as a synergistic set of positive psychological resources between social support and subjective well-being. In particular, we proposed the following hypotheses:

H1 Perceived social support is positively associated with life satisfaction (H1a) and positive affect (H1b), and negatively associated with negative affect (H1c) among college students learning online during the COVID-19 pandemic.

H2 PsyCap plays a mediating role between perceived social support and college students' subjective well-being, as indexed by life satisfaction $(\mathrm{H} 2 \mathrm{a})$, positive affect $(\mathrm{H} 2 \mathrm{~b})$, and negative affect $(\mathrm{H} 2 \mathrm{c})$.

\section{Methods}

\section{Data and Sample}

The present study is part of a research project on college students' living and learning conditions during the COVID19 pandemic in China. A convenient sampling was used by the project investigators to invite college students who had been learning online during the spring semester in August 2020 through their social networks. Two popular convenient communication apps among Chinese college students, Wechat and QQ, were employed to disseminate online questionnaires and collect data. As a result, a total of 670 college students from universities located in eastern, central, and western China voluntarily participated in the investigation. Because of the national implementation of "School's Out, But Class' On" plan in China (Zhou et al. 2020), all the invited students, regardless of where their universities were located, were believed to have sufficient home-based online experiences enabling their filling out the learning and living conditions questionnaire in this study (Lin 2021).

In the present study, 515 valid copies of questionnaires were finally identified, resulting in a good response rate of $76.87 \%$. Of the participants, $307(59.61 \%)$ were from universities in eastern China, 80 (15.53\%) were from universities in central China, and $117(22.72 \%)$ were from universities in western China; 11 (2.14\%) did not report university locations. There were 141 males $(27.38 \%)$ and 374 females $(72.62 \%)$. 150 students $(29.13 \%)$ were on the first year, $219(42.52 \%)$ were on the second year, 133 $(25.83 \%)$ were on the third year, and $13(2.52 \%)$ were on the fourth year or more. $232(45.05 \%)$ students majored in sciences and engineering, 216 (41.94\%) majored in humanities and social sciences, and 67 (13.01\%) majored in arts and sports. Eight $(1.55 \%)$ students were aged less than 18 years old, $485(94.17 \%)$ were aged 18-22 years old, and $22(4.27 \%)$ were aged $23-25$ years old.

Throughout the investigation, established ethical guidelines were followed. First, the author's department and the managing institute of the research project approved the research initiative in advance of data collection. Second, when investigation invitation was sent to participants, they were also informed of the contents and purpose of the research project. Third, before data collection, the participants were asked for their consent online to voluntarily participate in the anonymous online questionnaire investigation. The participants can stop answering the questionnaire at any time and for any reason.

\section{Variables}

\section{Subjective Well-Being}

College students' subjective well-being was measured based on Dierner's (1984) tripartite structure of subjective well-being and through the Positive and Negative Affect Scale (PANAS) adapted from Watson et al. (1988) as well as the widely used Overall Life Satisfaction Scale (OLS) (Casas et al. 2011). As for the measurement of positive and negative affect, college students were asked to indicate the extent to which they had experienced eight positive (e.g., 'interested', 'excited', and 'enthusiastic') and seven negative (e.g., 'upset', 'distressed', and 'scared') mood states during the fully online learning period through rating on a 
4-point Likert scale ranging from 1 (never) to 4 (always). Regarding the measurement of overall life satisfaction, college students were asked to report their satisfaction with life as a whole during those days of online learning through rating on a $0-10$, single-item scale, with 0 indicating the lowest life satisfaction and 10 the highest. Confirmative factor analysis (CFA) results indicated that the adapted PANAS had good construct validity $\left(\chi^{2}=345.412, \mathrm{df}=\right.$ 89, RMSEA $=0.075$, TLI $=0.923$, CFI $=0.935)$. The calculated Cronbach's $\alpha$ for the Positive Affect subscale (0.907) and the Negative Affect subscale (0.878) showed good reliability, respectively. Prior studies have corroborated the good psychometric properties of the OLS as a single-term scale (Tang 2019; Wanous et al. 1997).

\section{Psychological Capital (PsyCap)}

College students' PsyCap was measured with 18 items adapted from Luthans et al. (2007). The adapted PsyCap scale was comprised of four subscales: (1) efficacy (5 items, e.g., 'I feel confident helping to set targets/goals in my study area'); (2) hope (4 items, e.g., 'I can think of many ways to reach my current goals'); (3) resilience (5 items, e.g., 'I usually manage difficulties one way or another'; (4) optimism (4 items, e.g., 'I always look on the bright side of things'). College students were asked to rate themselves in terms of their navigating the fully online learning on a six-item Likert scale ranging from 1 (strongly disagree) to 6 (strongly agree). The calculated Cronbach's $\alpha$ for the overall PsyCap scale indicated good reliability (Cronbach's $\alpha=0.923$ ), as did its four subscales of efficacy, hope, resilience, and optimism (Cronbach's $\alpha=0.856,0.848,0.779$, and 0.756 , respectively). Firstorder CFA results showed that the adapted PsyCap scale had a good validity $\left(\chi^{2}=380.75\right.$, df $=129$, RMSEA $=$ 0.062 , TLI $=0.930, \mathrm{CFI}=0.941)$. Given that the four PsyCap factors were highly correlated, with standardized estimates ranging from 0.702 to 0.813 , a second-order factor structure was employed to represent college students' overall PsyCap. CFA results validated the overall PsyCap construct $\left(\chi^{2}=386.020, \mathrm{df}=131\right.$, RMSEA $=$ 0.061 , TLI $=0.930$, CFI $=0.940$ ), with high factor loadings ranging from 0.821 to 0.909 .

\section{Perceived Social Support}

College students' perceived social support was measured with the well-established 12-item Multidimensional Scale of Perceived Social Support (MSPSS) (Zimet et al. 1988). The three-dimensional scale measured perceived social support in terms of its related sources (i.e., family, friends, or significant others). College students were asked to rate their perceptions of social support during the fully online learning period on a six-point Likert scale ranging from 1 (strongly disagree) to 6 (strongly agree). The calculated Cronbach's $\alpha$ for the overall perceived social support scale indicated good reliability (Cronbach's $\alpha=0.910$ ), as did its three subscales of support of family, friends, and significant others (Cronbach's $\alpha=0.880,0.885$, and 0.911, respectively). First-order CFA results showed that the MSPSS had a good validity $\left(\chi^{2}=220.32, \mathrm{df}=51\right.$, RMSEA $=0.080$, TLI $=0.948$, CFI $=0.960)$. To demonstrate college students' perceptions of overall sources of social support, a second-order saturated model was constructed. CFA results validated the overall perceived social support construct with the same model fit as that of the first-order model and generated high factors loadings from 0.631 to 0.882 .

\section{Control Variables}

College students' gender, age, grade, and major were chosen as control variables to rule out potential confounding effects regarding the relationships of focus variables in this study (American College Health Association 2019; Luthans \& Youssef-Morga 2017).

\section{Data Analysis}

SPSS 24.0 and Mplus 7.0 software were used to conduct data analysis. First, SPSS software was used to conduct correlation analysis to examine the correlations among focus variables. Then Mplus software was used to conduct structural equation modeling (SEM) analysis with maximum likelihood estimation to examine the relationships among focus variables in this study as well as the mediating role of PsyCap between perceived social support and subjective well-being among college students learning online during the COVID-19 outbreak. The advantage of SEM has been recognized as being capable of dealing with measurement errors and estimating mediating effects within a single analytical model (Hayes 2009). In mediation analysis, the bias-corrected bootstrapping method with 1000 times of resampling was used to accurately calculate the point estimates of the $95 \%$ confidence intervals for the indirect effects (Hayes 2009). Based on $\mathrm{Hu}$ and Bentler (1999), the acceptable model fit indices were set at: rootmean-square error of approximation (RMSEA) $<0.08$; Tucker-Lewis index (TLI) $>0.90$; and comparative fit index $(\mathrm{CFI})>0.90$.

In addition, SPSS software was used to conduct Harman's single factor test, to examine possible common method bias in this study. With all items of the focus variables being loaded into one factor, less than $50 \%$ $(40.952 \%)$ of the total variance was explained. Since the 
common method bias was not of concern, there was no need to control for it in this study (Mat Roni 2014).

\section{Results}

\section{Correlation Analysis}

The results of correlation analysis are displayed in Table 1. As expected, perceived social support was positively correlated with life satisfaction $(\gamma=0.157, p<0.001)$ and positive affect $(\gamma=0.295, p<0.001)$ and negatively correlated with negative affect $(\gamma=-0.092, p<0.05)$. Likewise, PsyCap was positively correlated with life satisfaction $(\gamma=0.363, p<0.001)$ and positive affect $(\gamma=0.507, p<0.001)$ and negatively correlated with negative affect $(\gamma=-0.186, p<0.001)$. Additionally, perceived social support was positively correlated with PsyCap $(\gamma=0.422, p<0.001)$. Moreover, life satisfaction was positively correlated with positive affect $(\gamma=0.454$, $p<0.001)$ and negatively correlated with negative affect $(\gamma=-0.275, p<0.001)$. Positive affect was negatively correlated with negative affect $(\gamma=-0.187, p<0.001)$.

\section{Structural Equation Modeling (SEM)}

SEM analysis was conducted to examine the relationships among focus variables and the mediating role of PsyCap between perceived social support and subjective well-being. The three components of subjective well-being (i.e., life satisfaction, positive affect, and negative affect) were simultaneously analyzed as dependent variables. The results are illustrated in Fig. 1.

As shown in Fig. 1, a relatively large proportion (i.e., $25.3 \%, 16.8 \%$, and $34.6 \%$, respectively) of the variance in PsyCap, life satisfaction, and positive affect was explained by the model, respectively, while a relatively low proportion $(6.2 \%)$ of the negative affect variance was accounted for in the model. Moreover, the model fit indices generated by the SEM $\left(\chi^{2}=2553.386, \quad \mathrm{df}=1306\right.$; RMSEA $=0.043<0.08 ; \quad$ CFI $=0.907>0.90 ; \quad$ TLI $=$ $0.900>0.90)$ showed a good model fit ( $\mathrm{Hu} \&$ Bentler 1999). Control variables were considered for all the structural relationships among the focus variables.

The measurement part of the model generated high loadings of first-order factors on the corresponding secondorder latent constructs (i.e., perceived social support and PsyCap). The structural part of the SEM generated significant total effects of perceived social support on life satisfaction $(\beta=0.179, \quad p<0.001), \quad$ positive affect ( $\beta=0.361, p<0.001)$, and negative affect $(\beta=-0.128$, $p<0.05)$ without the inclusion of the mediating variable of PsyCap. The results support that perceived social support is positively associated with life satisfaction (H1a) and positive affect (H1b) and negatively associated with negative affect (H1c) among college students learning online during the COVID-19 pandemic.

Perceived social support was not directly related to life satisfaction $(\beta=-0.007, p>0.05)$ and negative affect $(\beta=-0.022, p>0.05)$ but directly related to positive affect $(\beta=0.110, p<0.05)$. Perceived social support is significantly related to PsyCap $(\beta=0.490, p<0.001)$. PsyCap is significantly and positively associated with life satisfaction $(\beta=0.380, p<0.001)$ and positive affect $(\beta=0.512, p<0.001)$ and significantly and negatively associated with negative affect $(\beta=-0.217, p<0.001)$.

Table 2 shows the mediating effect of PsyCap between perceived social support and subjective well-being. PsyCap fully mediated the relationship between perceived social support and life satisfaction $(\beta=0.186, p<0.001,95 \%$ CI: 0.110 to 0.263 ) as well as the relationship between perceived social support and negative affect $(\beta=-0.106$, $p<0.01$, 95\% CI: -0.176 to -0.037$)$. PsyCap partially mediated the relationship between perceived social support

Table 1 Results of correlation analysis

\begin{tabular}{lllll}
\hline & 1 & 2 & 3 & 4 \\
\hline 1.Life satisfaction & 1 & & & \\
2.Positive affect & $0.454^{* * *}$ & 1 & & \\
3.Negative affect & $-0.275^{* * *}$ & $-0.187^{* * *}$ & 1 & 1 \\
4.PsyCap & $0.363^{* * *}$ & $0.507^{* * *}$ & $-0.186^{* * *}$ & $0.422^{* * *}$ \\
5.Perceived social support & $0.157^{* * *}$ & $0.295^{* * *}$ & $-0.092^{*}$ & 4.09 \\
M & 7.49 & 2.90 & 2.45 & 0.59 \\
SD & 1.84 & 0.51 & 0.59 & 0.74 \\
\hline
\end{tabular}

Note. Standardized coefficients are reported

$* p<0.05$

$* * * p<0.001$ 
Fig. 1 The SEM results. Standardized coefficients are reported. FA $=$ family, $\mathrm{FR}=$ friends, $\mathrm{SO}=$ significant others, PS $=$ perceived social support, $\mathrm{EF}=$ efficacy, $\mathrm{HO}=$ hope, $\mathrm{RE}=$ resilience, $\mathrm{OP}=$ optimism, $\mathrm{PC}=$ PsyCap, $\mathrm{LS}=$ life satisfaction, $\mathrm{PA}=$ positive affect, $\mathrm{NA}=$ negative affect. $* * * p<0.001, * p<0.05$

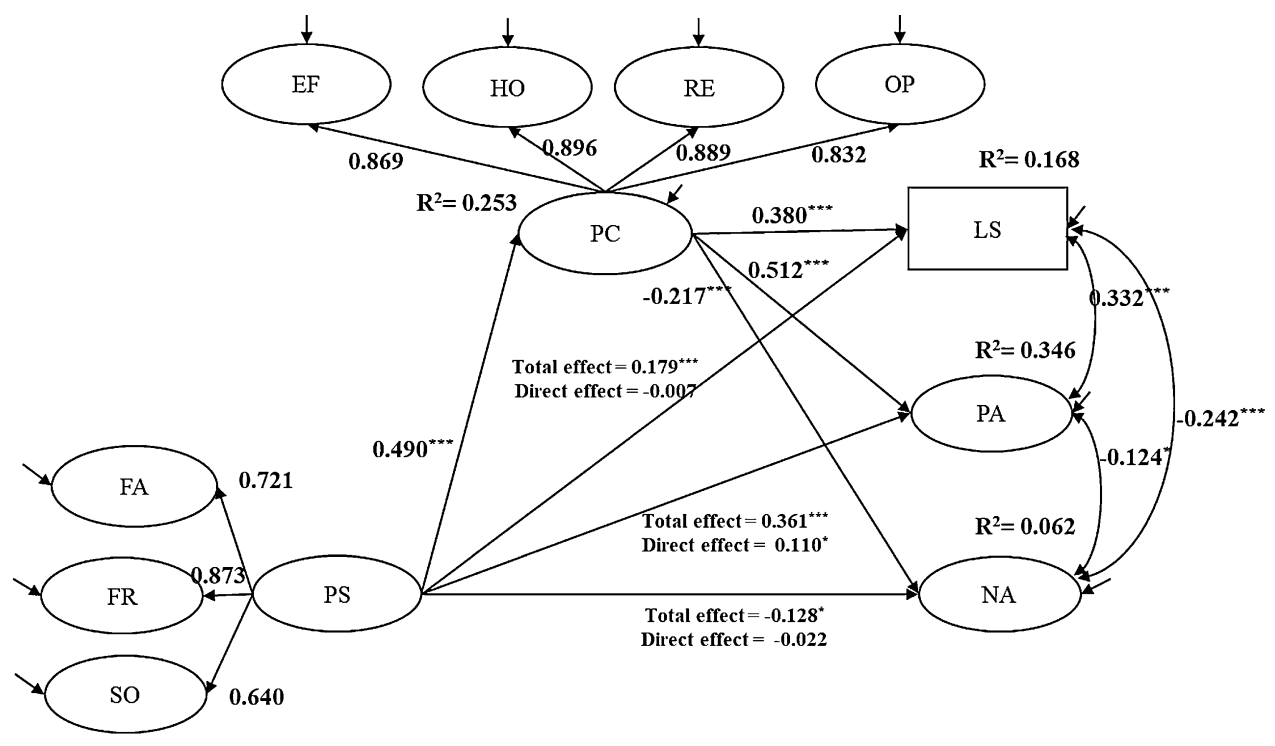

Table 2 Mediating effect of PsyCap

\begin{tabular}{|c|c|c|c|c|c|}
\hline & \multicolumn{2}{|c|}{ Direct effects } & \multicolumn{2}{|c|}{ Indirect effects } & \multirow[t]{2}{*}{ Indirect effects $95 \%$ Bootstrap CIs } \\
\hline & $\beta$ & S.E & B & S.E & \\
\hline Perceived social support $\rightarrow$ PsyCap $\rightarrow$ life satisfaction & -0.007 & 0.056 & $0.186^{* * *}$ & 0.031 & {$[0.110,0.263]$} \\
\hline Perceived social support $\rightarrow$ PsyCap $\rightarrow$ positive affect & $0.110^{*}$ & 0.054 & $0.251^{* * *}$ & 0.033 & {$[0.177,0.325]$} \\
\hline Perceived social support $\rightarrow$ PsyCap $\rightarrow$ negative affect & -0.022 & 0.063 & $-0.106^{* *}$ & 0.031 & {$[-0.176,-0.037]$} \\
\hline
\end{tabular}

Note: Standardized coefficients are reported

$* p<0.05$

$* * p<0.01$

$* * * p<0.001$

and positive affect ( $\beta=0.251, p<0.001,95 \%$ CI: 0.177 to 0.325$)$. Thus, the results support that PsyCap plays a mediating role between perceived social support and college students' subjective well-being, as indexed by life satisfaction (H2a), positive affect (H2b), and negative affect (H2c).

\section{Discussion}

Against the backdrop of heightened uncertainties caused by the COVID-19 pandemic, universities and colleges in China in the spring semester turned to fully online teaching modality in a short time to minimize the educational disruption (Zhou et al. 2020). As a group of population with high prevalence rates of pre-existing negative mood symptomatology in normal times, college students have suffered exacerbated loss of subjective well-being due to the pandemic-induced uncertainties and fears and the challenges of unexpected shifting to online learning mode (Cao et al. 2020; Wong 2020; Ye et al. 2020). To echo the increasing calls for urgent research and immediate solutions protecting the subjective well-being of college students (Chen et al. 2020; Grubic et al. 2020), we in the present study examined the relationships among perceived social support, PsyCap, and college students' subjective well-being in the context of online learning during the COVID-19 pandemic.

The study reveals a positive relationship between perceived social support and college students' subjective wellbeing, as indicated by increased life satisfaction and positive affect and reduced negative affect. Although this 
relationship has been repeatedly evidenced in various areas and among different population groups, it does shed important light on the development of effective approaches to the subjective well-being of college students during the COVID-19 pandemic. That is, timely and genuine social support, in instrumental, informational, or emotional forms, from significant others (i.e., family, friends, and teachers) can be helpful for college students to cope with life challenges and, more importantly, to overcome the online learning shock during the COVID-19 pandemic (Saltzman et al. 2020). This echoes the calls of the World Health Organization (WHO) for being supportive for each other and working together as one community to maintain mental well-being at the time of crisis (WHO, 2020).

The study reveals an important mediating role of PsyCap in connecting perceived social support and subjective well-being. This is in line with findings in previous studies denoting that perceived social support fosters PsyCap, which in turn fuels positive cognitive appraisals and emotional states (Rabenu et al. 2016; Youssef-Morgan \& Luthans 2015). This indicates the importance of PsyCap in internalizing the external social resources and maintaining positive psychosocial functioning (Karademas 2006; Ozbay et al. 2007). On the one hand, when faced with overwhelming online learning challenges during the COVID-19 outbreak, college students with sufficient assistance from family, friends, and teachers tend to hold positive attitudes toward difficulties (optimism), stick to their learning plan and overcome obstacles (hope), build confidence in performing tasks (efficacy), and sustain their efforts to retain progress in face of setbacks (resilience). On the other hand, college students who are equipped with high PsyCap would be able to act flexibly and adaptively to meet the online learning demands and maintain subjective well-being (Hefner \& Eisenberg 2009; Rabenu et al. 2016). The research findings contribute to the mechanisms through which perceived social support from significant others contributes to college students' subjective well-being in the context of online learning during the COVID-19 pandemic (Grubic et al. 2020). That is, effective external support embedded within college students' social networks may be characterized by its sufficient capabilities to stimulate a set of positive personal resources (i.e., efficacy, hope, resilience, and optimism), which enables college students to successfully cope with the stressful online learning experiences during the period of crisis (Saltzman et al. 2020).

The study reveals that a relatively high proportion of variance in the positive components of subjective wellbeing, namely, life satisfaction (16.8\%) and positive affect $(34.6 \%)$, was explained in the SEM analysis, while a relatively low proportion of variance in the negative component of negative affect (6.2\%) was explained in the model.
This may be due to two reasons. One is that both constructs of perceived social support and PsyCap are positive in nature, thus being more likely to trigger positive states and generate positive appraisals toward life quality (YoussefMorgan \& Luthans 2015). The other is that college students as an already-stressed population group have suffered heightened levels of negative mood states during the COVID-19 pandemic (Grubic et al. 2020). This may limit the roles of social support and PsyCap as positive coping strategies in buffering against negative affect.

\section{Implications for Practice}

The results provided some practical implications for attending to college students' subjective well-being in the context of online learning during the outbreak of COVID19. First, the study suggests that having access to various sources of social support, including teachers, parents, and friends can be beneficial for college students to counteract the pandemic-induced uncertainties and fears, overcome the online learning shock, and maintain subjective wellbeing (Rabenu et al. 2016). On college students' side, although the campus closure and physical distancing has significantly reduced face-to-face interactions and communications, college students can still benefit from utilizing the technology (e.g., phone calls and messages, social media and chat apps, and virtual meeting) to stay socially connected. For instance, they may take advantage of video chat apps to share feelings and emotions with teachers, family members, and friends and proactively seek out for help when in need during the period of online learning (WHO, 2020).

For university instructional practice, this suggests that the provision of support services for both course learning and psychosocial adjustment would be contributive to students' subjective well-being (Lambert \& Schuck 2021). Unlike traditional classes that provide sufficient opportunities of face-to-face interactions and in-time feedback and praise, online classes face challenges in promoting effective teacher-students interactions and communications (Gasevic 2020; Wong 2020). This necessitates teachers' proactive learning support that helps close student-teacher psychological distance and promote engaging and meaningful online learning experiences (Turley \& Graham 2019). For instance, instead of delivering courses through a direct approach in front of the computer screen, teachers may take advantage of scaffolding feedback (e.g., successive hints and partial solutions) and positive praise to boost self-regulated learning skills, stimulate student interest in contents, and facilitate understanding (Guo et al. 2019). Apart from adoption of synchronous teaching model through video conferencing or live lectures, teachers may 
also utilize asynchronous forms of teaching (e.g., discussion forums and email) to promote online interactions and communications, improve online tutorial and coaching quality, and help students regain positive feelings toward performing online tasks (Turley \& Graham 2019).

On the part of parents, positive and supportive parentchild relationships have been identified as crucial coping resources for college students to address stressors and maintain mental well-being (Macalli et al. 2020). Empirical evidence has shown that parenting practices exert significant influences on parent-child relationships, which contribute to the immediate home environment shaping students' subjective well-being (Hwang \& Jung 2021). Research also suggests that while appropriate parental involvement is beneficial for children to keep academically engaged and stay mentally healthy, intensively intervening in the lives of children as helicopter parents would inversely undermine college students' autonomy and willingness to exercise control over psychosocial functioning (Kouros et al., 2017). Hence, parenting practices that entail autonomy support are essential. It is therefore suggested that parents with children learning at home during the pandemic build a supportive relationship with children through showing respect for their decision, providing appropriate autonomy support, and encouraging them to develop problem-solving skills, to help college students maintain positively engaged with their lives (Chen et al. 2018). For those with children already suffering heightened levels of stress, parents may keep an eye out for signs of mental problems and seek for external mental health services and professional support when in need. Parents may also engage college students in offline physical activities on a regular basis to help them relieve stress, anxiety, and negative mood state and regain positive feelings (UNICEF 2020).

Second, this study suggests that PsyCap as a set of positive psychological resources can be relied on by college students to internalize external social support and retain subjective well-being (Ozbay et al. 2007; Saltzman et al. 2020). In practice, university should monitor college students' PsyCap levels with online instruments and deliver tailored resources and services for students learning online during the pandemic, especially for those who have suffered psychological deficiency (Grubic et al. 2020). Since PsyCap and its components are open to development (Luthans \& Youssef-Morgan 2017), it is feasible for universities and colleges to implement psychological interventions and integrate training tasks or activities designed to develop psychological resources of efficacy, hope, resilience, and optimism into online lectures or counseling services, to help students foster PsyCap, curb negative mood and stress, and keep mental well-being (Baticulon et al. 2021; Luthans \& Youssef-Morgan 2017). The well- established PsyCap Intervention model (PCI) has suggested a range of development strategies (Luthans et al. 2006), such as task-related role-play for hope-building, opportunity-seeking activities for optimism training, group interactions and communications for efficacy training, and reflective exercises for resilience improvement (Salanova \& Ortega-Maldonado 2019). In addition to the universal interventions, university mental health professionals may adopt selective online micro-interventions to at-risk groups or students identified through the online instruments to help them enhance PsyCap in areas of deficiency and retain subjective well-being (Allen-Meares et al. 2013).

\section{Conclusion and Limitations}

This study promoted empirical understanding of the relationships among perceived social support, PsyCap, and subjective well-being through an investigation of a sample of Chinese college students learning online during the COVID-19 pandemic. The findings of the study were in line with previous studies (Aluh \& Onu 2020; Saltzman et al. 2020) indicating positive relationships between perceived social support and subjective well-being, as indicated by (high levels of) life satisfaction, and positive affective and (low levels of) negative affect (Busseri \& Sadava 2011). Particularly, the study contributed to the literature by identifying PsyCap as an important psychological mechanism underlying these relationships (Hefner \& Eisenberg 2009; Luthans et al. 2007).

Despite the significance of the research, there are still some limitations. First, participants were selected through convenience sampling, limiting the representativeness of the data and hence the results. More studies employing a nationally representative sample of college students should be conducted. Second, the research design was cross-sectional in nature and cannot conduct causal inference. Future studies may employ longitudinal research design to conclude causality. Finally, although efficacy, hope, resilience, and optimism were all captured as constituents of the high-order PsyCap construct, they also demonstrated differences in their roles and functions (Luthans et al. 2017). Future studies may examine different mediating effects of the four PsyCap components on the relationship between perceived social support and subjective well-being among college students in the context of online learning during the COVID-19 pandemic.

Acknowledgements The work described in this paper was supported by the Education and Teaching Reform Funds for the Central Universities (English as the medium of instruction), Southeast University, China and by the Fundamental Research Funds for the Central Universities, Southeast University, China. 


\section{Declarations}

Conflict of interest The authors declare that there is no conflict of interest.

\section{References}

Allen-Meares, P., Montgomery, K. L., \& Kim, J. S. (2013). Schoolbased social work interventions: a cross-national systematic review. Social Work, 58(3), 253-262.

Aluh, D. O., \& Onu, J. U. (2020). The need for psychosocial support amid COVID-19 crises in Nigeria. Psychological Trauma: Theory, Research, Practice and Policy, 12(5), 557-558.

American Campus Communities (2020). College students' perspective on mental health during COVID-19. https://www.americancampus.com/about-us/media/ fall2020studentmentalhealthreport.

Ao, D., \& Wang, Z. J. (2020). Mental health status and its demographic factors among college students during the epidemic of Covid-19. Population and Development, 21(5), 122-128.

Arnett, J. J. (2000). Emerging adulthood: a theory of development from the late teens through the early twenties. American Psychologist, 55, 469-480.

American College Health Association. (2019). American College Health Association: National College health assessment II: Reference group executive summary spring 2019. https://doi.org/10.1080/24745332.2019.1620558

Avey, J. B., Luthans, F., \& Jensen, S. M. (2009). Psychological capital: a positive resource for combating employee stress and turnover. Human Resource Management, 48(5), 677-693. https://doi.org/10.1002/hrm.20294

Bao, W. (2020). COVID-19 and online teaching in higher education: a case study of Peking University. Human Behavior and Emerging Technologies. https://doi.org/10.1002/hbe2.191

Baticulon, R. E., Sy, J. J., Alberto, N., Baron, M., Mabulay, R., Rizada, L., Tiu, C., Clarion, C. A., \& Reyes, J. (2021). Barriers to online learning in the time of COVID-19: a national survey of medical students in the Philippines. Medical Science Educator. https://doi.org/10.1007/s40670-021-01231-z

Besser, A., Flett, G. L., and Zeigler-Hill, V. 2020 Adaptability to a sudden transition to online learning during the COVID-19 pandemic: understanding the challenges for students. Scholarship of Teaching and Learning in Psychology. doi: https://doi.org/10.1037/st10000198 [Epub ahead of print].

Burns, D., Dagnall, N., \& Holt, M. (2020). Assessing the impact of the COVID-19 pandemic on student wellbeing at universities in the United Kingdom: a conceptual analysis. Frontiers in Education, $\quad 5, \quad 582882$. https://doi.org/10.3389/feduc.2020.582882

Busseri, M. A., \& Sadava, S. W. (2011). A review of the tripartite structure of subjective well-being: Implications for conceptualization, operationalization, and synthesis. Personality and Social Psychology Review, 15(3), 290-314.

Cao, W., Fang, Z., Hou, G., Han, M., Xu, X., Dong, J., \& Zheng, J. (2020). The psychological impact of the COVID-19 epidemic on college students in China. Psychiatry Research, 287, 112934. https://doi.org/10.1016/j.psychres.2020.112934

Casas, F., Coenders, G., González, M., Malo, S., Bertran, I., \& Figuer, C. (2011). Testing the relationship between parents' and their children's subjective well-being. Journal of Happiness Studies, 13(6), 1031-1051. https://doi.org/10.1007/s10902-011-9305-3

Chang, J. H., Yuan, Y. X., \& Wang, D. (2020). Mental health status and its influencing factors among college students during the epidemic of COVID-19. Journal of Southern Medical University, 36(8), 697-700.

Chen, R., Liang, S., Peng, Y., Li, X., Chen, J., Tang, S., \& Zhao, J. (2020). Mental health status and change in living rhythms among college students in China during the COVID-19 pandemic: a large-scale survey. Journal of Psychosomatic Research, 137, e110219.

Chen, T. 2020 A college student's viral Tweet about the stress of online school shows how education is being impacted by the coronavirus. Accessed 10 October 2020. https://www.buzzfeednews.com/article/tanyachen/students-saytheyre-struggling-with-online-classes-in.

Chen, X., Fan, X., Cheung, H. Y., \& Wu, J. (2018). The subjective well-being of academically gifted students in the Chinese cultural context. School Psychology International, 39(3), 291-311. https://doi.org/10.1177/0143034318773788

Cobb, S. (1976). Social support as a moderator of life stress. Psychosomatic Medicine, 38(5), 300-314.

Cowley, M. 2020 Students report less motivation, higher stress levels with the transition to online learning. Accessed 10 October 2020. https://www.ntdaily.com/students-report-less-motivation-higherstress-levels-with-the-transition-to-online-learning/

de Cates, A., Stranges, S., Blake, A., \& Weich, S. (2015). Mental well-being: an important outcome for mental health services? The British Journal of Psychiatry: THe Journal of Mental Science, 207(3), 195-197. https://doi.org/10.1192/bjp.bp.114.158329

Dhawan, S. (2020). Online Learning: a panacea in the time of COVID-19 crisis. Journal of Educational Technology Systems, 49(1), 5-22. https://doi.org/10.1177/0047239520934018

Diener, E. (1984). Subjective well-being. Psychological Bulletin, 95, 542-575.

Diener, E. (1994). Assessing subjective well-being: progress and opportunities. Social Indicators Research, 31(2), 103-157.

Diener, E., Oishi, S., \& Lucas, R. E. (2002). Subjective well-being: The science of happiness and life satisfaction. In C. R. Snyder \& S. J. Lopez (Eds.), Handbook of Positive Psychology. New York: Oxford University Press.

Ettman, C. K., Abdalla, S. M., Cohen, G. H., Sampson, L., Vivier, P. M., \& Galea, S. (2020). Prevalence of depression symptoms in US adults before and during the COVID-19 pandemic. JAMA New Open., 3(9), e2019686. https://doi.org/10.1001/jamanetworkopen.2020.19686

Fan, X., \& Lu, M. (2019). Testing the effect of perceived social support on left-behind children's mental well-being in mainland China: the mediation role of resilience. Children and Youth Services

Review. https://doi.org/10.1016/j.childyouth.2019.104695

Gasevic, D. 2020 COVID-19: The steep learning curve for online education. Accessed $10 \quad$ October 2020. https://lens.monash.edu/@education/2020/04/26/1380195/covid19-the-steep-learning-curve-for-online-education.

Griffiths, D. S., Winstanley, D., \& Gabriel, Y. (2005). Learning Shock: the trauma of return to formal learning. Management Learning, $\quad 36(3)$, https://doi.org/10.1177/1350507605055347

Grubic, N., Badovinac, S., \& Johri, A. M. (2020). Student mental health in the midst of the COVID-19 pandemic: a call for further research and immediate solutions. International Journal of Social Psychiatry. https://doi.org/10.1177/0020764020925108

Guo, W., Lau, K. L., \& Wei, J. (2019). Teacher feedback and students' self-regulated learning in mathematics: a comparison between a high-achieving and a low-achieving secondary schools. Studies in Educational Evaluation, 63, 48-58. https://doi.org/10.1016/j.stueduc.2019.07.001 
Hasan, N., \& Bao, Y. (2020). Impact of "e-learning crack-up" perception on psychological distress among college students during COVID-19 pandemic: a mediating role of "fear of academic year loss. Children and Youth Services Review, 118, e105355.

Hayes, A. F. (2009). Beyond Baron and Kenny: statistical mediation analysis in the new millennium. Communication Monographs, 76(4), 408-420.

Hefner, J., \& Eisenberg, D. (2009). Social support and mental health among college students. The American Journal of Orthopsychiatry, 79(4), 491-499. https://doi.org/10.1037/a0016918

House, J. S., Umberson, D., \& Landis, K. R. (1988). Structures and processes of social support. Annual Review of Sociology, 14, 293-318.

Hu, L. T., \& Bentler, P. M. (1999). Cutoff criteria for fit indexes in covariance structure analysis: conventional criteria versus new alternatives. Structural Equation Modeling: A Multidisciplinary Journal, 6(1), 1-55.

Hung, M., Licari, F. W., Hon, E. S., Lauren, E., Su, S., Birmingham, W. C., \& Lipsky, M. S. (2020). In an era of uncertainty: impact of COVID-19 on dental education. Journal of Dental Education. https://doi.org/10.1002/jdd.12404

Hwang, W., \& Jung, E. (2021). Parenting practices, parent-child relationship, and perceived academic control in college students. Journal of Adult Development, 28, 37-49. https://doi.org/10.1007/s10804-020-09346-0

Karademas, E. C. (2006). Self-efficacy, social support and well-being. Personality and Individual Differences, 40(6), 1281-1290. https://doi.org/10.1016/j.paid.2005.10.019

Kieny, C., Flores, G., Ingenhaag, M. et al 2020 Healthy, wealthy, wise, and happy? Assessing age differences in evaluative and emotional well-being among mature adults from five low- and middle-income countries. Social Indicators Research Doi: https://doi.org/10.1007/s11205-020-02515-4

Lambert, R., \& Schuck, R. (2021). "The wall now between us": teaching math to students with disabilities during the COVID spring of 2020. The Asia-Pacific Educational Researcher., 30, 289-298. https://doi.org/10.1007/s40299-021-00568-8

Lin, T. J. (2021). Exploring the differences in Taiwanese university students' online learning task value, goal orientation, and selfefficacy before and after the COVID-19 outbreak. The AsiaPacific Educational Researcher. https://doi.org/10.1007/s40299-021-00553-1

Luthans, F., Avey, J. B., Avolio, B. J., Norman, S. M., \& Combs, G. M. (2006). Psychological capital development: toward a microintervention. Journal of Organizational Behavior, 27, 387-393.

Luthans, F., Youssef, C. M., \& Avolio, B. J. (2007). Psychological capital. Oxford University Press.

Luthans, F., \& Youssef-Morgan, C. M. (2017). Psychological capital: an evidence-based positive approach. Annual Review of Organizational Psychology and Organizational Behavior, 4(1), 339-366.

https://doi.org/10.1146/annurev-orgpsych-032516-113324

Luthans, F., Youssef-Morgan, C. M., \& Avolio, B. (2015). Psychological Capital and Beyond. Oxford Univ. Press.

Lyons, Z., Wilcox, H., Leung, L., \& Dearsley, O. (2020). COVID-19 and the mental well-being of Australian medical students: impact, concerns and coping strategies used. Australasian Psychiatry: Bulletin of Royal Australian and New Zealand College of Psychiatrists, 28(6), 649-652. https://doi.org/10.1177/1039856220947945

Macalli, M., Côté, S., \& Tzourio, C. (2020). Perceived parental support in childhood and adolescence as a tool for mental health screening in students: a longitudinal study in the i-Share cohort. Journal of Affective Disorders, 266, 512-519. https://doi.org/10.1016/j.jad.2020.02.009
Mat Roni, S. (2014). Introduction to SPSS. Edith Cowan University, SOAR Centre.

Ozbay, F., Johnson, D. C., Dimoulas, E., Morgan, C. A., Charney, D., \& Southwick, S. 2007 Social support and resilience to stress: from neurobiology to clinical practice. Psychiatry (Edgmont (Pa. : Township)) 4(5): 35-40

Pan, K. Y., Kok, A., Eikelenboom, M., Horsfall, M., Jörg, F., Luteijn, R. A., Rhebergen, D., Oppen, P. V., Giltay, E. J., \& Penninx, B. (2021). The mental health impact of the COVID-19 pandemic on people with and without depressive, anxiety, or obsessivecompulsive disorders: a longitudinal study of three Dutch casecontrol cohorts. The Lancet. Psychiatry, 8(2), 121-129. https://doi.org/10.1016/S2215-0366(20)30491-0

Pinkerton, J., \& Dolan, P. (2007). Family support, social capital, resilience and adolescent coping. Child \& Family Social Work, 12(3),

219-228. https://doi.org/10.1111/j.1365-2206.2007.00497.x

Qi, M., Zhou, S.-J., Guo, Z.-C., Zhang, L.-G., Min, H.-J., Li, X.-M., \& Chen, J.-X. (2020). The effect of social support on mental health in Chinese adolescents during the outbreak of COVID-19. Journal of Adolescent Health. https://doi.org/10.1016/j.jadohealth.2020.07.001

Rabenu, E., Yaniv, E., \& Elizur, D. (2016). The relationship between psychological capital, coping with stress, well-being, and performance. Current Psychology, 36(4), 875-887. https://doi.org/10.1007/s12144-016-9477-4

Ren, Y., \& Ji, B. (2019). Correlation between perceived social support and loneliness among Chinese adolescents: mediating effects of psychological capital. Psychiatria Danubina, 31(4), 421-428. https://doi.org/10.24869/psyd.2019.421

Salanova, M., \& Ortega-Maldonado, A. (2019). Psychological capital development in organizations: An integrative review of evidence-based intervention programs. In L. Van Zyl \& S. Rothmann Sr. (Eds.), Positive psychological intervention design and protocols for multi-cultural contexts. Cham: Springer.

Saltzman, L. Y., Hansel, T. C., \& Bordnick, P. S. (2020). Loneliness, isolation, and social support factors in post-COVID-19 mental health. Psychological Trauma: Theory, Research, Practice and Policy, 12(S1), S55-S57. https://doi.org/10.1037/tra0000703

Tang, Y. P. (2019). Immigration status and adolescent life satisfaction: an international comparative analysis based on PISA 2015. Journal of Happiness Studies, 20(5), 1499-1518.

The Moderating Role of Sex and Ethnicity. (2017). Kouros, C.D., Pruitt, M.M., Ekas, N.V. et al. (2017). Helicopter Parenting, Autonomy Support, and College Students' Mental Health and Well-being. Journal of Child and Family Studies, 26, 939-949. https://doi.org/10.1007/s10826-016-0614-3

The Novel Coronavirus Pneumonia Emergency Response Epidemiology Team. (2020). The epidemiological characteristics of an outbreak of 2019 Novel Coronavirus Diseases (COVID-19) China, 2020. China CDC Weekly, 2(8), 113-122. https://doi.org/10.46234/ccdcw2020.032

The State Council Information Office of the P. R. China 2020 Fighting COVID-19: China in action. Accessed 9 October 2020. http://www.scio.gov.cn/zfbps/ndhf/42312/Document/1682142/ 1682142.htm.

The World Health Organization 2020 Basic psychosocial skills: A guide for COVID-19 responders. Accessed 20 October 2020. https://interagencystandingcommittee.org/system/files/2020-05/ Basic\%20Psychosocial\%20Skills\%20A\%20Guide\%20for\%20COVID-19\%20Responders.pdf.

Turley, C., \& Graham, C. (2019). Interaction, student satisfaction, and teacher time investment in online high school courses. Journal of Online Learning Research, 5(2), 169-198.

United Nations International Children's Emergency Fund 2020 Supporting your child's mental health during COVID-19 school 
returns. $\quad$ Accessed $15 \quad$ October 2020. https://www.unicef.org/coronavirus/supporting-your-childsmental-health-during-covid-19-school-return.

Wang, P., Xiong, Z., \& Yang, H. (2018). Relationship of mental health, social support, and coping styles among graduate students: evidence from Chinese universities. Iranian Journal of Public Health, 47(5), 689-697.

Wang, X., Cai, L., Qian, J., \& Peng, J. (2014). Social support moderates stress effects on depression. International Journal of Mental Health Systems, $8(1), \quad 41$. https://doi.org/10.1186/1752-4458-8-41

Wanous, J. P., Reichers, A. E., \& Hudy, M. J. (1997). Overall job satisfaction: how good are single-item measures? Journal of Applied Psychology, 82(2), 247-252.

Watson, D., Clark, L. A., \& Tellegen, A. (1988). Development and validation of brief measures of positive and negative affect: the PANAS scales. Journal of Personality and Social Psychology, 54(6), 1063-1070. https://doi.org/10.1037//0022-3514.54.6.1063

Wong M. 2020 Online teaching: A prospective educational model?. $\begin{array}{llll}\text { Accessed } & 10 & \text { October }\end{array}$ http://www.china.org.cn/opinion/2020-04/20/ content_75952841.htm.

Wu, Y., Han, X. R., \& Qian, D. F. (2020). Study on status of mental health among college students during the COVID-19 epidemic. Chinese Journal of Health Education, 36(08), 697-700.

Ye, Z., Yang, X., Zeng, C., Wang, Y., Shen, Z., Li, X., \& Lin, D. 2020 Resilience, Social Support, and Coping as Mediators between COVID-19-related Stressful Experiences and Acute Stress Disorder among College Students in China. Applied psychology. Health and well-being https://doi.org/10.1111/aphw.12211. Advance online publication. https://doi.org/10.1111/aphw.12211

Youssef-Morgan, C. M., \& Luthans, F. (2015). Psychological capital and well-being. Stress and Health, 31(3), 180-188. https://doi.org/10.1002/smi.2623

Zhang, J., \& Zheng, Y. (2017). How do academic stress and leisure activities influence college students' emotional well-being? A daily diary investigation. Journal of Adolescence, 60, 114-118. https://doi.org/10.1016/j.adolescence.2017.08.003

Zhang, X. 2020 Online learning and technical breakthroughs. $\begin{array}{llll}\text { Accessed } & 15 & \text { October } & 2020 .\end{array}$ http://www.chinatoday.com.cn/ctenglish/2018/cs/202008/ t20200827_800218925.html.

Zhou, L., Li, F., Wu, S., \& Zhou, M. (2020). "School's out, but class's on", the largest online education in the world today: taking China's practical exploration during the COVID-19 epidemic prevention and control as an example. Best Evidence in Chinese Education, 4(2), 501-519. https://doi.org/10.15354/bece.20.ar023

Zimet, G. D., Dahlem, N. W., Zimet, S. G., \& Farley, G. K. (1988). The multidimensional scale of perceived social support. Journal of Personality Assessment, 52, 30-41.

Publisher's Note Springer Nature remains neutral with regard to jurisdictional claims in published maps and institutional affiliations. 